\title{
First principles study of structural stability and site preference in $\mathrm{Co}_{3}(\mathrm{~W}, \mathrm{X})$
}

\author{
Sri Raghunath Joshi ${ }^{\text {a }}$, K.V. Vamsi, and S. Karthikeyan \\ Department of Materials Engineering, Indian institute of Science, Bangalore 560012, India
}

\begin{abstract}
Since the discovery $[1]$ of $\gamma^{\prime}$ precipitate $\left(\mathrm{L1}_{2}-\mathrm{Co}_{3}(\mathrm{Al}, \mathrm{W})\right)$ in the $\mathrm{Co}-\mathrm{Al}-\mathrm{W}$ ternary system, there has been an increased interest in Co-based superalloys. Since these alloys have two phase microstructures $\left(\gamma+\gamma^{\prime}\right)$ similar to Ni-based superalloys [2], they are viable candidates in high temperature applications, particularly in land-based turbines. The role of alloying on stability of the $\gamma^{\prime}$ phase has been an active area of research. In this study, electronic structure calculations were done to probe the effect of alloying in $\mathrm{Co}_{3} \mathrm{~W}$ with $\mathrm{L}_{2}$ structure. Compositions of type $\mathrm{Co}_{3}(\mathrm{~W}, X)$, (where $\mathrm{X} / \mathrm{Y}=\mathrm{Mn}, \mathrm{Fe}, \mathrm{Ni}, \mathrm{Pt}, \mathrm{Cr}, \mathrm{Al}, \mathrm{Si}, \mathrm{V}, \mathrm{W}, \mathrm{Ta}, \mathrm{Ti}, \mathrm{Nb}, \mathrm{Hf}, \mathrm{Zr}$ and Mo) were studied. Effect of alloying on equilibrium lattice parameters and ground state energies was used to calculate Vegard's coefficients and site preference related data. The effect of alloying on the stability of the $\mathrm{L}_{2}$ structure vis $a$ vis other geometrically close packed ordered structures was also studied for a range of $\mathrm{Co}_{3} \mathrm{X}$ compounds. Results suggest that the penchant of element for the W sublattice can be predicted by comparing heats of formation of $\mathrm{Co}_{3} \mathrm{X}$ in different structures.
\end{abstract}

\section{Introduction}

Superalloys are widely used in gas-turbine industry for land-based power generation systems as well as in aircraft engines. For power generation applications, where the fuel is not as "clean" as in the case of aircraft engines, sulphidization resistance is an important criterion for material selection. In this regard Co-base superalloys are promising candidates for land-based turbine applications [3]. Interest in Co-base alloys has been renewed since the discovery of $\mathrm{L}_{2}$ structured cuboidal precipitates of the composition $\mathrm{Co}_{3}(\mathrm{Al}, \mathrm{W})$ in the Co-Al-W system [1]. In this class of Co-base alloys, the microstructure consists of $\mathrm{L1}_{2}\left(\gamma^{\prime}\right)$ precipitates of composition $\mathrm{Co}_{3}(\mathrm{Al}, \mathrm{W})$ in a Co-rich fcc $(\gamma)$ matrix [1,46] and in this aspect, the microstructure is akin to Ni-base superalloys typically used in gas turbine applications [2]. Single crystal [7] and polycrystalline [4,5] Co-Al-W base superalloys have been tested for mechanical properties such as elastic moduli [7], high temperature creep resistance and ductility [8]. It has been shown that Cobase superalloys fared similar to some Ni-base superalloys at $900{ }^{\circ} \mathrm{C}$ [4]. Pyczak et al. [9] have shown that the deformation microstructures in Co-Al-W alloys are also similar to the ones in Ni base superalloys.

Given that these materials are relatively immature, it is important to understand the role of alloying elements on phase stability. In this context, a keen area of research has been to find quaternary alloying additions that would enhance the stability of the $\gamma^{\prime}$ phase and widen the composition domain where it is stable $[10,11]$. This

\footnotetext{
${ }^{a}$ Corresponding author: karthik@materials.iisc.ernet.in
}

is particularly important since the phase is stable only when the composition is close to $\mathrm{Co}_{3}\left(\mathrm{Al}_{0.5} \mathrm{~W}_{0.5}\right)$ [12]. An understanding of alloying effects on phase stability is also expected to assist in designing alloys with optimum volume fraction of $\gamma^{\prime}$ so that the desired mechanical properties are met. To expedite this effort, many researchers have used first principles calculations based on density functional theory, to generate baseline data and to support experimental alloy design [10]. These efforts have focused primarily on predicting equilibrium lattice parameters [12], elastic constants $[12,13]$ and ideal strength of $\mathrm{Ll}_{2}-\mathrm{Co}_{3}(\mathrm{Al}, \mathrm{W})$, [14] and to understand site preference $[15,16]$ of various alloying elements in $\gamma^{\prime}$. In this study we contribute to this effort by computing the effect of several alloying elements-Mn, Fe, Ni, Pt, Cr , Al, $\mathrm{Si}, \mathrm{V}, \mathrm{W}, \mathrm{Ta}, \mathrm{Ti}, \mathrm{Nb}, \mathrm{Hf}, \mathrm{Zr}$ and Mo-on lattice parameter of $\mathrm{Co}_{3} \mathrm{~W}$ using first principles electronic structure methods. In this study, we also explore site preference of these alloying elements. In these calculations, the base alloy was chosen to be $\mathrm{Co}_{3} \mathrm{~W}$ (in $\mathrm{L1}_{2}$ ) and not $\mathrm{Co}_{3} \mathrm{Al}$. This is because $\mathrm{Co}_{3} \mathrm{Al}$ is not a stable compound formed in the CoAl phase diagram, whereas $\mathrm{Co}_{3} \mathrm{~W}$ is stable in the $\mathrm{DO}_{19}$ structure (and structurally similar to $\mathrm{L}_{2}$ ). We attribute the occurrence of $\mathrm{L}_{2}-\mathrm{Co}_{3}(\mathrm{Al}, \mathrm{W})$ to the $\mathrm{L}_{2}$ stabilizing effect of $\mathrm{Al}$ in $\mathrm{Co}_{3} \mathrm{~W}$. The site preference data and Vegard's parameters are expected to be useful for identifying other stabilizers of the $\mathrm{L} 1_{2}$ phase and for designing alloys with desired misfit.

While Co-Al-W base superalloys systems remain the most promising for the presence of an $\mathrm{L1}_{2}$ based precipitate, alternative candidates for $\gamma^{\prime}$ other than $\mathrm{Co}_{3}(\mathrm{Al}, \mathrm{W})$ have not been well explored. Since $\mathrm{L} 1_{2}$ phases

This is an Open Access article distributed under the terms of the Creative Commons Attribution License 4.0, which permits unrestricted use, distribution, and reproduction in any medium, provided the original work is properly cited. 
have been reported in Co-Ti [17], Co-Ta [18] and Co$\mathrm{V}[19,20]$ systems, it is imperative that the possibility of stabilizing other $\mathrm{Co}_{3} \mathrm{X}$ type compounds in $\mathrm{L}_{2}$ structure be explored. In this context, $\mathrm{Xu}$ et al. [21] have studied the structural stability of $\mathrm{Co}_{3} \mathrm{X}$ compounds $(\mathrm{X}=\mathrm{Ti}$, Ta, $\mathrm{V}, \mathrm{W}$ and $\mathrm{Al}$ ) in $\mathrm{L}_{2}$ as well as in $\mathrm{DO}_{19}$ structures. They have shown that $\mathrm{Ti}, \mathrm{Ta}$ and $\mathrm{V}$ are strong $\mathrm{L}_{2}$ stabilisers whereas $\mathrm{W}$ and $\mathrm{Al}$ are $\mathrm{DO}_{19}$ stabilisers. Additionally, Omori et al. [22] have shown that heats of formation of $\mathrm{Co}_{3} \mathrm{X}$ compounds in $\mathrm{L}_{2}$ and $\mathrm{DO}_{19}$ structures can give vital and indirect information about partitioning behaviour of alloying elements to various phases in a Co-Al-W system. Clearly, calculations in $\mathrm{Co}_{3} \mathrm{X}$ not only help explore novel $\mathrm{L1}_{2}$ compositions, but also provide insights for stabilizing $\mathrm{L}_{2}-\mathrm{Co}_{3}(\mathrm{Al}, \mathrm{W})$. Moreover, it has been shown [23,24], that the structural energy of $\mathrm{Ni}_{3} \mathrm{X}$ in different structures can be correlated well with various planar fault energies. A similar effort in $\mathrm{Co}_{3} \mathrm{X}$ will provide insights into the role of alloying on fault energies in Co-Al-W, Co-Al-W-X and Co-X systems. In this context, the second aim of this work is to compute the energy of various $\mathrm{Co}_{3} \mathrm{X}$ compounds in geometrically close packed structures $-\mathrm{L}_{2}, \mathrm{DO}_{19}, \mathrm{DO}_{22}$, $\mathrm{DO}_{24}$, and $\mathrm{DO}_{a}$ for various alloying elements. In current literature, this data is available only for a limited set of alloying elements and only in $\mathrm{L}_{2}$ and $\mathrm{DO}_{19}$ structures.

In the first part of this paper, we describe the computational methodology employed. Subsequently, site preference and Vegard's coefficients of various alloying elements in $\mathrm{Co}_{3} \mathrm{~W}$, and structural stability of $\mathrm{Co}_{3} \mathrm{X}$ in different structures is presented. In the final section, the possibility of predicting site preference of $\mathrm{X}$ in $\mathrm{Co}_{3} \mathrm{~W}$ from the stability of $\mathrm{Co}_{3} \mathrm{X}$ is explored.

\section{Method of calculation}

Density functional theory calculations were performed using Vienna Abinitio Simulation Package ${ }^{T M}$ (VASP 4.6) [25,26] within the MedeA environment [27]. Projected Augmented Wave method [28,29] was used with generalised gradient approximation based pseudopotentials where parameterization was in the scheme of Perdew and Wang (PW - GGA) [30]. Electrons in the outermost shell were only considered for calculations involving most elements except $\mathrm{Mo}, \mathrm{Cr}$ and $\mathrm{Nb}$ where the semicore p-shell electrons were also taken into consideration. The electron wave functions were expanded using a plane wave basis set with a cutoff energy of $550 \mathrm{eV}$. The Brillouin zone was divided using a K-point spacing of $0.1 \AA^{-1}$. A Methfessel-Paxton type smearing (of $1^{\text {st }}$ order) was applied to the wave function over a width of $0.1 \mathrm{eV}$. The system size was of 32 atoms. Local atomic relaxation was allowed in all cases. All calculations were run until a convergence of $10^{-5} \mathrm{eV}$ was attained in total energy and the forces on individual atoms were less than $0.02 \mathrm{eV} / \AA$.

In the first set of calculation, site preference and Vegard's coefficients of alloying elements in $\mathrm{L1}_{2}-\mathrm{Co}_{3} \mathrm{~W}$ was computed. With $\mathrm{L}_{2}-\mathrm{Co}_{3} \mathrm{~W}$ as the reference, alloying elements were added to the $\mathrm{Co}$ and $\mathrm{W}$ sublattices to result in compositions of $\left(\mathrm{Co}_{23} \mathrm{X}\right) \mathrm{W}_{8}$ and $\mathrm{Co}_{24}\left(\mathrm{~W}_{7} \mathrm{X}\right)$ respectively. Equilibrium lattice parameters as well as ground state total energies were obtained for these compositions. From these calculations, site preference
Table 1. Lattice parameters $a^{\prime}, b^{\prime}$ and $c^{\prime}$ used to constrain $\mathrm{DO}_{19}$, $\mathrm{DO}_{22}, \mathrm{DO}_{24}$ and $\mathrm{DO}_{a}$ to the equilibrium lattice parameters of $\mathrm{L}_{2}$.

\begin{tabular}{|l|l|l|l|l|}
\hline & $\mathbf{D O}_{\mathbf{1 9}}$ & $\mathbf{D O}_{\mathbf{2 2}}$ & $\mathbf{D O}_{\mathbf{2 4}}$ & $\mathbf{D O}_{\mathbf{a}}$ \\
\hline$a^{\prime} / a_{L 1_{2}}$ & $\sqrt{2}$ & 1 & $\sqrt{2}$ & $\sqrt{2}$ \\
\hline$b^{\prime} / a_{L 1_{2}}$ & $\sqrt{2}$ & 1 & $\sqrt{2}$ & $\sqrt{4 / 3}$ \\
\hline$c^{\prime} / a_{L 1_{2}}$ & $\sqrt{4 / 3}$ & 2 & $4 \sqrt{1 / 3}$ & $\sqrt{3 / 2}$ \\
\hline
\end{tabular}

(with reference to $\mathrm{W}$ ) was estimated by computing the enthalpy change, $\Delta E_{3}$ associated with the following equation which involves swapping of $\mathrm{X}$ in the Co sublattice with a $\mathrm{W}$ atom in the $\mathrm{W}$ sublattice:

$$
\mathrm{Co}_{24} W_{8}+\mathrm{Co}_{23} X W_{8} \rightarrow \mathrm{Co}_{24} W_{7} X+\mathrm{Co}_{23} W W_{8}
$$

$$
\Delta E_{3}=\mathrm{E}_{C o_{24}\left(W_{7} X\right)}^{L 12}+\mathrm{E}_{\left(C_{23} W\right) W_{8}}^{L 12}-\mathrm{E}_{\left(C_{23} X\right) W_{8}}^{L 12}-\mathrm{E}_{C_{24} W_{8}}^{L 12}
$$

$\mathrm{E}_{C o_{24}\left(W_{7} X\right)}^{L 12}, \mathrm{E}_{\left(C o_{23} W\right) W_{8}}^{L 12}, \mathrm{E}_{\left(C o_{23} X\right) W_{8}}^{L 12}$ and $\mathrm{E}_{C o_{24} W_{8}}^{L 12}$ are the ground states energies of the compositions indicated in the subscript and in $\mathrm{L}_{2}$ structure. Positive values of $\Delta E_{3}$ suggest a weaker preference (than $\mathrm{W}$ ) for the Co sublattice. Using the equilibrium lattice parameters of $\left(\mathrm{Co}_{23} \mathrm{X}\right) \mathrm{W}_{8}$ and $\mathrm{Co}_{24}\left(\mathrm{~W}_{7} \mathrm{X}\right)$ and comparing with that of $\mathrm{Co}_{3} \mathrm{~W}$, all in $\mathrm{L}_{2}$ structure, Vegard's coefficient $(\gamma)$ of these alloying additions in different sublattices was calculated:

$$
\begin{gathered}
\Upsilon_{W}=\frac{a_{C_{24}\left(W_{7} X\right)}-a_{C o_{3} W}}{\left(\frac{1}{8}\right) a_{C o_{3} W}} \\
\Upsilon_{C o}=\frac{a_{\left(C_{23} X\right) W_{8}}-a_{C o_{3} W}}{\left(\frac{1}{24}\right) a_{C o_{3} W}}
\end{gathered}
$$

where $a_{\mathrm{CO}_{24}\left(W_{7} \mathrm{X}\right)}$ and $a_{\left(\mathrm{Co}_{23} \mathrm{X}\right) W_{8}}$ are the equilibrium lattice parameters (for a 4 atom unit cell) for $\mathrm{X}$ in $\mathrm{W}$ and $\mathrm{Co}$ sublattices respectively and $a_{\mathrm{Co}_{3} W}$ is the equilibrium lattice parameter of $\mathrm{CO}_{3} \mathrm{~W}$.

For the second part of the study, $\mathrm{Co}_{3} \mathrm{X}$ compounds were simulated in $\mathrm{L}_{2}, \mathrm{DO}_{19}, \mathrm{DO}_{22}, \mathrm{DO}_{24}$, and $\mathrm{DO}_{a}$. Two sets of calculations were done. In the first set, the lattice parameters were adjusted for each structure so that it achieved the lowest ground state energy for that structure (i.e., fully relaxed). From this, equilibrium lattice parameters were calculated for $\mathrm{Co}_{3} \mathrm{X}$ in all structures. In the second set of calculations, $\mathrm{Co}_{3} \mathrm{X}$ type structures in $\mathrm{DO}_{19}, \mathrm{DO}_{22}, \mathrm{DO}_{24}$ and $\mathrm{DO}_{a}$ were constrained to lattice parameters which resulted in the same atomic volume, coordination, and bond lengths as found in the equilibriated $\mathrm{Co}_{3} \mathrm{X}$ in $\mathrm{L}_{2}$, and ground state energy was evaluated. Table 1 shows the appropriate choice of constrained lattice parameters for each structure.

Cohesive energies and heats of formation were calculated for these compounds using:

$$
\begin{gathered}
\mathrm{E}_{c, C o_{3} X}^{S}=\frac{\mathrm{E}_{C o_{3} X}^{S}-3 \mathrm{E}_{C o}^{\text {iso }}-\mathrm{E}_{X}^{\text {iso }}}{4} \\
\mathrm{H}_{c, C o_{3} X}^{S}=\frac{\mathrm{E}_{C o_{3} X}^{S}-3 E_{C o_{1}}^{h c p}-E_{X_{1}}^{\text {native }}}{4}
\end{gathered}
$$




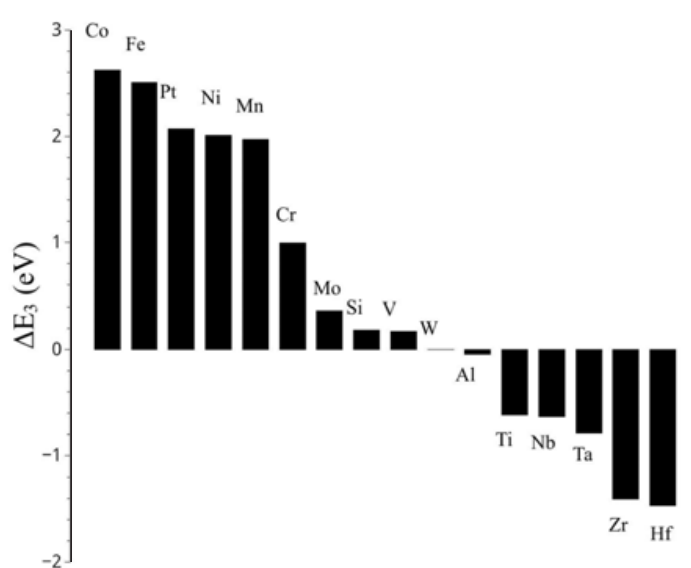

Figure 1. - Site preference behaviour as evaluated from $\Delta E_{3}$ for different alloying elements.

where $\mathrm{E}_{c, \mathrm{Co}_{3} \mathrm{X}}^{S}$ is the cohesive energy of $\mathrm{Co}_{3} \mathrm{X}$ in structure $\mathrm{S} . \mathrm{E}_{C o}^{i s o}$ and $\mathrm{E}_{X}^{i s o}$ are the ground state energies of Co and $\mathrm{X}$ in an isolated state. $\mathrm{H}_{c, \mathrm{Co}_{3} \mathrm{X}}$ is the heat of formation of $\mathrm{Co}_{3} \mathrm{X}$ in structure $\mathrm{S}, E_{\mathrm{Co}_{1}}^{h c p}$ is the ground state energy of one atom of Co in hcp structure, and $E_{X_{1}}^{\text {native }}$ is the ground state energy of one atom of $\mathrm{X}$ in its native structure (as indicated in Table 2).

\section{Results \& Discussion}

\subsection{Alloying effects}

Figure 1 shows the values of $\Delta E_{3}$ for several alloying elements. $\Delta E_{3}$ is an indicator of the element's preference for a sublattice ( $\mathrm{Co}$ or $\mathrm{W}$ ) in $\mathrm{Co}_{3} \mathrm{~W}$. Positive values of $\Delta E_{3}$ for an element $\mathrm{X}$ suggest that the element has a greater affinity (than $\mathrm{W}$ ) to go to the Co sublattice in $\mathrm{Co}_{3} \mathrm{~W}$. Negative values of $\Delta E_{3}$ suggest that the alloying element prefers the $\mathrm{W}$ sublattice even more than $\mathrm{W}$ does. Thus elements with negative $\Delta E_{3}$ strongly prefer W sublattice. Positive $\Delta E_{3}$ does not imply a preference for the Colattice. Instead what it means is that the alloying element has a greater affinity (than W) to go to the Co sublattice in $\mathrm{Co}_{3} \mathrm{~W}$. From this one can conclude that $\mathrm{Hf}, \mathrm{Zr}$, Ti, $\mathrm{Ta}, \mathrm{Nb}$ and $\mathrm{Al}$ prefer the $\mathrm{W}$ sublattice more so than $\mathrm{W}$, whereas, elements with high positive values such as $\mathrm{Pt}, \mathrm{Fe}, \mathrm{Ni}, \mathrm{Mn}$ are likely to occupy the Co sublattice. Elements with small positive values (i.e. $\mathrm{Cr}, \mathrm{Mo}, \mathrm{V}, \mathrm{Si}$ ) are expected to equipartition to different extents between the two sublattices.

Figure 2 shows the Vegard's coefficients for various elements in the two sublattices. It is observed that that $\Upsilon_{C o}$ for most alloying elements is positive, given the small size of the Co atom. This suggests that their presence in the Co sublattice would result in a significant increase in $\gamma^{\prime}$ lattice parameter. In comparison, $\Upsilon_{W}$ takes on both positive and negative values, given the intermediate size of the $\mathrm{W}$ atom.

Unlike Ni base superalloys, Co-Al-W based superalloys have a positive misfit, i.e, $a_{\gamma^{\prime}}>a_{\gamma}$ by $\sim 0.5 \%$. This can result in high energy semi-coherent $\gamma / \gamma^{\prime}$ interfaces with a tendency to coarsen rapidly; resulting in a loss of mechanical properties. In this context, alloying additions

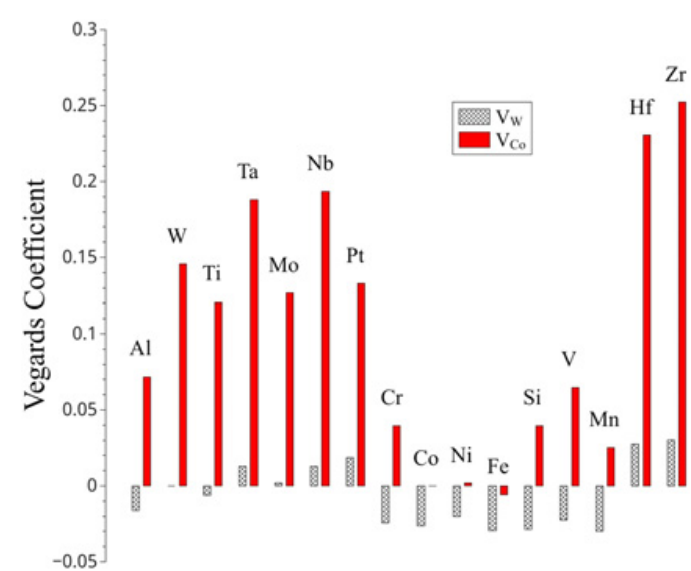

Figure 2. Vegards coefficients of different alloying elements in the two sublattices of $\mathrm{L}_{2}-\mathrm{Co}_{3} \mathrm{~W}$.

that increase the lattice parameter of $\gamma$ and decrease that of $\gamma^{\prime}$ are attractive. While Vegard's coefficients in $\gamma$ were not calculated in this study, one can use site preference data from Fig. 1 in conjunction with the Vegard's coefficient, to predict if an alloying element would reduce the lattice parameter of $\gamma^{\prime}$; if such an alloying element goes to the sublattice of its thermodynamic choice, then in that sublattice it must have a negative Vegard's coefficient. This criterion limits the possible candidates to $\mathrm{Cr}, \mathrm{V}, \mathrm{Si}, \mathrm{Al}$ and to a minor extent, Fe.

In accordance with Hume-Rothery rules [31], for an alloying element to prefer a sublattice it has to be similar to the primary atom in that sublattice in its size and in its chemical nature. Vegard's coefficient is an appropriate measure of the size difference between the alloying element and "solvent" atom. The chemical similarity between the solvent atom and the alloying addition has been previously related to the number of valence electrons in the two elements [12]. However, since most alloying elements considered in this study are transition metals and have multiple valences, we have instead used the electronegativity parameter $\left(\Phi^{*}\right)$, proposed by Miedema et al. [33] as a measure of chemical similarity between the alloying element and the matrix. In Fig. 3, various alloying elements have been mapped in the space of Vegard's coefficient (in specific sublattice) and the difference in $\Phi^{*}$ between $X$ and the solvent atom in that sublatice; Fig. $3 \mathrm{a}$ is for the Co sublattice, while $3 b$ is for the $\mathrm{W}$ sublattice. In these figures, the radius of the circles is proportional to the absolute value of $\Delta E_{3}$. Additionally positive values of $\Delta E_{3}$ are color coded red and negative ones are coded blue. Larger discontinuous blue circles indicate elements with a strong preference for the $\mathrm{W}$ sublattice, while large continuous red circles indicate a strong preference for the Co sublattice.

From these figures, it can be seen that there is a cluster of the elements that prefer the Co sublattice and a second cluster of elements-diametrically on the other side of the map-that prefer the $\mathrm{W}$ sublattice. In the map for the Co sublattice, it is observed that elements that strongly partition to the Co sublattice (i.e., large red circles), are clustered around $(0,0)$ and are thus similar in size and chemical nature to Co. Likewise, in the map for the W 

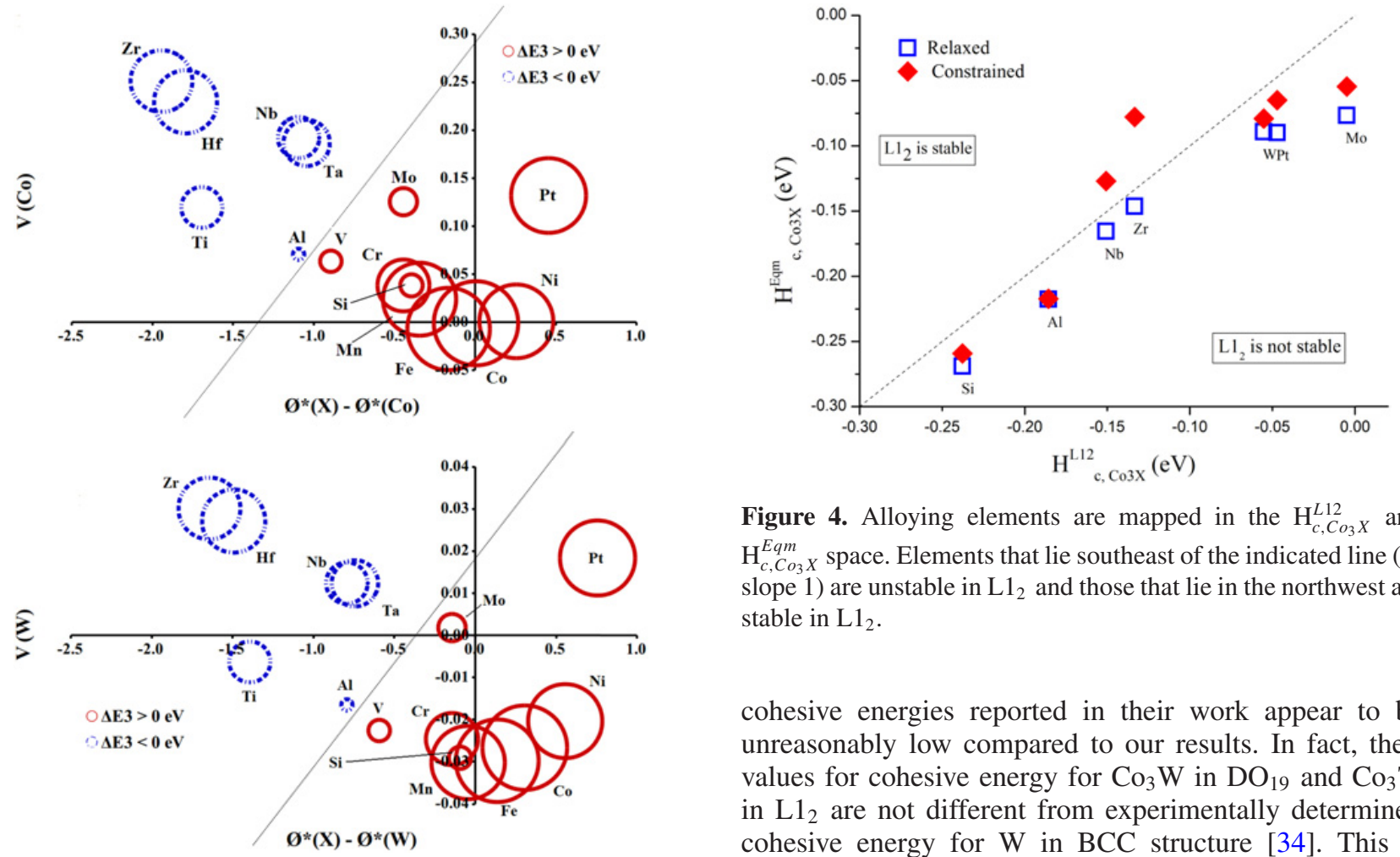

Figure 4. Alloying elements are mapped in the $\mathrm{H}_{c, \mathrm{Co}_{3} X}^{L 12}$ and $\mathrm{H}_{c, C o_{3} X}^{E q m}$ space. Elements that lie southeast of the indicated line (of slope 1) are unstable in $\mathrm{L}_{2}$ and those that lie in the northwest are stable in $\mathrm{L1}_{2}$.

cohesive energies reported in their work appear to be unreasonably low compared to our results. In fact, their values for cohesive energy for $\mathrm{Co}_{3} \mathrm{~W}$ in $\mathrm{DO}_{19}$ and $\mathrm{Co}_{3} \mathrm{Ti}$ in $\mathrm{L}_{2}$ are not different from experimentally determined cohesive energy for $\mathrm{W}$ in BCC structure [34]. This is improbable since this would imply that $\mathrm{Co}_{3} \mathrm{~W}, \mathrm{Co}_{3} \mathrm{Ti}$ and $\mathrm{W}$ would have similar melting points, which is known not to be true. Note: melting points of most metals and intermetallics scale linearly with cohesive energy [34]. In contrast, the cohesive energy values derived in this work are reasonable and scale well with known melting points of these intermetallics.

From the cohesive energy data, it is noted that $\mathrm{Co}_{3} \mathrm{X}$ Mo, both of which are in the same group as W. In these figures, we have indicated a crude demarcation between the elements that prefer the $\mathrm{W}$ sublattice and others. These maps can be useful in designing alloys. For instance, in the map for Co sublattice, it can be concluded that for elements to strongly prefer the $\mathrm{W}$ sublattice, they have to be deep in the second quadrant $(\mathrm{x}<<0, \mathrm{y}>>0)$. Since the Miedema electronegativity is known for most metals in the periodic table, and a rough estimate for the Vegard's coefficient can also be derived from the difference in the metallic radii (also readily available across the periodic table) of the metal and cobalt, the site preference of any metal in $\mathrm{Co}_{3} \mathrm{~W}$ can be predicted approximately. For instance, it is predicted that $\mathrm{Y}$ and Sc will prefer the W sublattice even more than $\mathrm{Zr}$ and $\mathrm{Hf}$. It will be interesting to check if this prediction is borne out.

\subsection{Structural stability}

The cohesive energies and heats of formation of $\mathrm{Co}_{3} \mathrm{X}$ type compounds computed in $\mathrm{DO}_{19}, \mathrm{DO}_{22}, \mathrm{DO}_{24}$ and $\mathrm{DO}_{\mathrm{a}}$ structures (constrained and fully relaxed) are compared with those of $\mathrm{L}_{2}$ in Table 2 . The heats of formation of these compounds are in good agreement with computational results of Xu et al. [21] and Omori et al. [22] as well as with experimental results where available. This validates the procedure employed for calculating these parameters. Cohesive energy of $\mathrm{Co}_{3} \mathrm{X}(\mathrm{X}=\mathrm{Ti}, \mathrm{Ta}, \mathrm{Al}, \mathrm{W}$ and V) has been reported by $\mathrm{Xu}$ et al. [21]. However, for fully relaxed calculations, while $\mathrm{CO}_{3} \mathrm{Si}$ is most stable in $\mathrm{DO}_{22}$ and $\mathrm{Co}_{3} \mathrm{Al}$ is most stable in $\mathrm{DO}_{\mathrm{a}}$. For all other alloying elements, $\mathrm{DO}_{19}$ is the stablest structure in the fully relaxed condition.

A comparison of the heat of formation of $\mathrm{H}_{c, \mathrm{Co}_{3} \mathrm{X}}^{\mathrm{L} 12}$ against that in its equilibrium structure $\mathrm{H}_{c, C_{3} X}^{E q m}$ reveals important features. Such a map is shown in figure 4. The blue rectangles correspond to the $\mathrm{H}_{c, C_{3} \mathrm{X}}^{L 12}$ and $\mathrm{H}_{c, \mathrm{Co}_{3} X}^{E q m}$. values of alloying elements. Only those elements are shown whose values lie to the right of the unity line, i.e., whose equilibrium structure has a lower heat of formation and is more stable than $\mathrm{L}_{2}$. Alloying additions whose values lie closer to the line (such as $\mathrm{Nb}$ and $\mathrm{Zr}$ ) have comparable values of $\mathrm{H}_{c, \mathrm{Co}_{3} \mathrm{Xqm}}^{\mathrm{E}}$ and $\mathrm{H}_{c, C_{3} X}^{L 12}$ and it is reasonable to assume that $\mathrm{Co}_{3} \mathrm{Nb}$ and $\mathrm{Co}_{3} \mathrm{Zr}$ can be stabilized in $\mathrm{L1}_{2}$ with relative ease perhaps by alloying. In contrast, stabilizing $\mathrm{Co}_{3} \mathrm{Mo}$ in $\mathrm{L}_{2}$ may be difficult since Mo is further away from the line. This argument has also been put forth by Omori et al. [22]. Another interesting feature emerges by comparing the heat of formation, $\mathrm{H}_{c, C_{3} X}^{L 12}$ against that in the equilibrium structure constrained to $\mathrm{L}_{2}$ dimensions, i.e., $\mathrm{H}_{c, \text { Co } o_{3} X}^{E q m \text {, constr. }}$. These trends are also shown in Fig. 4. The red diamonds are a comparison between $\mathrm{H}_{c, C_{3} X}^{L 12}$ and $\mathrm{H}_{c, \mathrm{Co}_{3} \mathrm{X} X}^{E q m \text {, onstr. }}$. Here it is seen that by constraining 
Table 2. Cohesive energies and heats of formation of $\mathrm{Co}_{3} \mathrm{X}$ type compounds in different structures, (fully relaxed and constrained to $\mathrm{L} 1_{2}$ lattice parameters). The cohesive energies of these compounds in the constrained structures are in parenthesis below. The lowest value of the cohesive energy, for each compound is highlighted in bold face font.

\begin{tabular}{|c|c|c|c|c|c|c|c|c|c|c|}
\hline \multirow{2}{*}{\multicolumn{2}{|c|}{\begin{tabular}{|l|l|} 
& \\
& $\begin{array}{l}\text { Native } \\
\text { Structure }\end{array}$ \\
\end{tabular}}} & \multirow{2}{*}{\multicolumn{5}{|c|}{ Cohesive Energy of $\mathrm{Co}_{3} \mathrm{X}(\mathrm{eV} / \mathrm{atom})$}} & \multicolumn{4}{|c|}{ Heat of formation of $\mathrm{Co}_{3} \mathrm{X}(\mathrm{kJ} / \mathrm{mol})$} \\
\hline & & & & & & & \multicolumn{2}{|c|}{$\mathbf{L 1}_{2}$} & \multicolumn{2}{|r|}{$\mathrm{DO}_{19}$} \\
\hline $\mathbf{X}$ & & $\mathbf{L 1}_{2}$ & $\mathrm{DO}_{19}$ & $\mathrm{DO}_{22}$ & $\mathrm{DO}_{24}$ & $\mathrm{DO}_{\mathrm{a}}$ & Calc. & Ref & Calc. & Ref \\
\hline Al & FCC & -4.9650 & $\begin{array}{l}-4.9901 \\
(-4.9891) \\
\end{array}$ & $\begin{array}{l}-4.9858 \\
(-4.9819) \\
\end{array}$ & $\begin{array}{l}-4.9768 \\
(-4.9764)\end{array}$ & $\begin{array}{l}-\mathbf{4 . 9 9 6 9} \\
(-4.9965) \\
\end{array}$ & -17.92 & $\begin{array}{l}-17.97 \\
{[22]}\end{array}$ & -20.34 & $-20.41[22]$ \\
\hline $\mathbf{W}$ & $\mathrm{BCC}$ & -6.0738 & $\begin{array}{l}-\mathbf{6 . 1 0 7 7} \\
(-6.0977)\end{array}$ & $\begin{array}{l}-6.0451 \\
(-6.0440)\end{array}$ & $\begin{array}{l}-6.0916 \\
(-6.0838)\end{array}$ & $\begin{array}{l}-6.0836 \\
(--6.0787)\end{array}$ & -5.33 & $\begin{array}{l}-4.81 \\
{[22]}\end{array}$ & -8.60 & $-8.07[35]^{\operatorname{expt}}$ \\
\hline Ti & $\mathrm{HCP}$ & -5.5573 & $\begin{array}{l}-5.5260 \\
(-5.5087)\end{array}$ & $\begin{array}{l}-5.5055 \\
(-5.4987)\end{array}$ & $\begin{array}{l}-5.5378 \\
(-5.5324)\end{array}$ & $\begin{array}{l}-5.5178 \\
(-5.4855)\end{array}$ & -24.32 & $\begin{array}{l}-25.88 \\
{[22]}\end{array}$ & -21.30 & $-22.67[22]$ \\
\hline Ta & $\mathrm{BCC}$ & -6.2733 & $\begin{array}{l}-6.2662 \\
(-6.2318)\end{array}$ & $\begin{array}{l}-6.1934 \\
(-6.1898)\end{array}$ & $\begin{array}{l}-6.2725 \\
(-6.2559)\end{array}$ & $\begin{array}{l}-6.2104 \\
(-6.2016)\end{array}$ & -24.16 & $\begin{array}{l}-23.44 \\
{[22]}\end{array}$ & -23.49 & $-22.92[22]$ \\
\hline Mo & $\mathrm{BCC}$ & -5.4762 & $\begin{array}{l}-\mathbf{5 . 5 2 9 5} \\
(-5.5257)\end{array}$ & $\begin{array}{l}-5.4832 \\
(-5.4588)\end{array}$ & $\begin{array}{l}-5.5010 \\
(-5.5001)\end{array}$ & $\begin{array}{l}-5.5215 \\
(-5.5025)\end{array}$ & -0.48 & $\begin{array}{l}-0.549 \\
{[36]}\end{array}$ & -5.62 & $-5.30[37]^{\operatorname{expt}}$ \\
\hline $\mathbf{N b}$ & $\mathrm{BCC}$ & -5.7852 & $\begin{array}{l}-\mathbf{5 . 7 9 9 9} \\
(-5.7614)\end{array}$ & $\begin{array}{l}-5.7246 \\
(-5.7208)\end{array}$ & $\begin{array}{l}-5.7953 \\
(-5.7756) \\
\end{array}$ & $\begin{array}{l}-5.7516 \\
(-5.7422) \\
\end{array}$ & -14.55 & $\begin{array}{l}-14.42 \\
{[22]}\end{array}$ & -15.97 & $-15.81[22]$ \\
\hline $\mathbf{P t}$ & FCC & -5.3380 & $\begin{array}{l}\mathbf{5 . 3 8 0 8} \\
(-5.3559)\end{array}$ & $\begin{array}{l}-5.3357 \\
(-5.3355)\end{array}$ & $\begin{array}{l}-5.3548 \\
(-5.3532)\end{array}$ & $\begin{array}{l}-5.3662 \\
(-5.3626)\end{array}$ & -4.54 & & -8.67 & \\
\hline $\mathrm{Cr}$ & $\mathrm{BCC}$ & -4.8739 & $\begin{array}{l}\mathbf{4 . 9 3 3 7} \\
(-4.9122)\end{array}$ & $\begin{array}{l}-4.8823 \\
(-4.8769)\end{array}$ & $\begin{array}{l}-4.8902 \\
(-4.8879) \\
\end{array}$ & $\begin{array}{l}-4.9234 \\
(-4.9159) \\
\end{array}$ & 4.84 & $2.36[22]$ & -0.94 & $-0.83[22]$ \\
\hline $\mathbf{N i}$ & FCC & -5.1977 & $\begin{array}{l}\mathbf{5 . 2 2 4 9} \\
(-5.2226)\end{array}$ & $\begin{array}{l}-5.1973 \\
(-5.1965)\end{array}$ & $\begin{array}{l}-5.2089 \\
(-5.2084)\end{array}$ & $\begin{array}{l}-5.2208 \\
(-5.2198)\end{array}$ & 0.48 & $0.50[22]$ & -2.15 & $-2.06[22]$ \\
\hline $\mathbf{F e}$ & $\mathrm{BCC}$ & -5.0213 & $\begin{array}{l}-\mathbf{5 . 1 6 5 0} \\
(-5.1223)\end{array}$ & $\begin{array}{l}-5.0423 \\
(-5.0405)\end{array}$ & $\begin{array}{l}-5.0187 \\
(-5.0185)\end{array}$ & $\begin{array}{l}-5.0571 \\
(-5.0526)\end{array}$ & 17.41 & $\begin{array}{l}17.29 \\
{[22]}\end{array}$ & 3.55 & $3.39[22]$ \\
\hline $\mathbf{S i}$ & $\begin{array}{l}\text { Diamond } \\
\text { cubic }\end{array}$ & -5.2979 & $\begin{array}{l}-5.3191 \\
(-5.3150)\end{array}$ & $\begin{array}{l}\mathbf{- 5 . 3 2 9 1} \\
(-5.3194)\end{array}$ & $\begin{array}{l}-5.3047 \\
(-5.2939)\end{array}$ & $\begin{array}{l}-5.3244 \\
(-5.3213)\end{array}$ & -22.93 & & -24.98 & \\
\hline V & $\mathrm{BCC}$ & -5.4281 & $\begin{array}{l}-5.4262 \\
(-5.4175)\end{array}$ & $\begin{array}{l}-5.3763 \\
(-5.3716)\end{array}$ & $\begin{array}{l}-5.4251 \\
(-5.4212)\end{array}$ & $\begin{array}{l}-5.1727 \\
(-4.8501)\end{array}$ & -16.70 & $\begin{array}{l}-17.05 \\
{[22]}\end{array}$ & -16.51 & $-16.79[22]$ \\
\hline Mn & $\mathrm{BCC}$ & -4.8518 & $\begin{array}{l}-4.8014 \\
(-4.7951)\end{array}$ & $\begin{array}{l}-4.8040 \\
(-4.7977)\end{array}$ & $\begin{array}{l}-4.8040 \\
(-4.7916)\end{array}$ & $\begin{array}{l}-4.8114 \\
(-4.7880)\end{array}$ & 0.32 & $3.52[22]$ & 5.19 & $7.61[22]$ \\
\hline Hf & $\mathrm{HCP}$ & -5.8218 & $\begin{array}{l}(-5.8129) \\
(-5.7606) \\
\end{array}$ & $\begin{array}{l}-5.7620 \\
(-5.7554) \\
\end{array}$ & $\begin{array}{l}-5.8133 \\
(-5.7910) \\
\end{array}$ & $\begin{array}{l}-5.8156 \\
(-5.7832)\end{array}$ & -21.45 & & -20.59 & \\
\hline $\mathbf{Z r}$ & $\mathrm{HCP}$ & -5.6057 & $\begin{array}{l}\mathbf{5 . 6 1 8 4} \\
(-5.5499)\end{array}$ & $\begin{array}{l}-5.5633 \\
(-5.5572)\end{array}$ & $\begin{array}{l}-5.6090 \\
(-5.5796)\end{array}$ & $\begin{array}{l}-5.6031 \\
(-5.5923)\end{array}$ & -12.89 & & -14.11 & \\
\hline
\end{tabular}

$\mathrm{Co}_{3} \mathrm{Nb}$ and $\mathrm{Co}_{3} \mathrm{Zr}, \mathrm{L1}_{2}$ structure becomes stabler than its unconstrained equilibrium structure. This is interesting because it suggests that $\mathrm{Co}_{3} \mathrm{X}$ can be stabilized in $\mathrm{L1}_{2}$ if its dimensions are constrained. One possible source of constraint could be the Co matrix itself from which the $\gamma^{\prime}$ precipitates. Another possible means of constraining $\mathrm{Co}_{3} \mathrm{X}$ may be by alloying. Thus this suggests that there may be possible means of stabilizing many $\mathrm{Co}_{3} \mathrm{X}$ compounds in $\mathrm{L}_{2}$.

\subsection{Structural stability and site preference in $\mathrm{Co}_{3} \mathrm{~W}$}

It is worthwhile considering if one can use $\mathrm{H}_{c, \mathrm{Co}_{3} X}^{L 12}$ to predict how the alloying element $\mathrm{X}$ would behave when introduced into $\mathrm{Co}_{3} \mathrm{~W}$. In Fig. $5, \Delta E_{3}$ is plotted as a function of $\mathrm{H}_{c, \mathrm{Co}_{3} X}^{L 12}-\mathrm{H}_{c, C o_{3} W}^{L 12}$. Reasonable correlation is observed; if for an element $\mathrm{X}, \mathrm{H}_{c, \mathrm{Co}_{3} \mathrm{X}}^{L 12}<\mathrm{H}_{c, \mathrm{Co}_{3} W}^{L 12}$, then it is highly likely that the element will prefer the W sublattice when introduced in $\mathrm{Co}_{3} \mathrm{~W}$. Since $\mathrm{H}_{c, C o_{3} X}^{L 12}$ calculations involve small systems (4 atoms), these are computationally much easier than computations of $\Delta E_{3}$ which are expensive given that at least four 32-atom calculations involving atomic relaxation have to be made

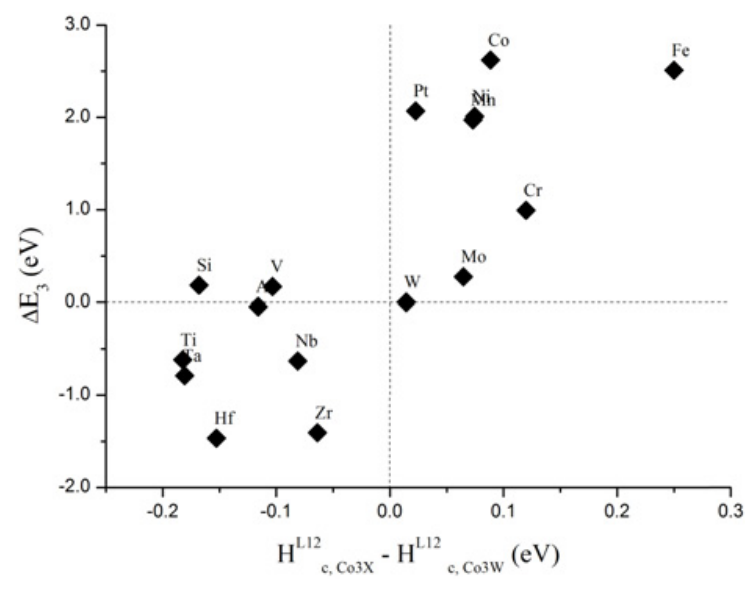

Figure 5. $\Delta E_{3}$ plotted as a function of $\mathrm{H}_{c, C o_{3} X}^{L 12}-\mathrm{H}_{c, C o_{3} W}^{L 12}$.

for each alloying element. In this context, computation of $\mathrm{H}_{c, C o_{3} \mathrm{X}}^{L 12}-\mathrm{H}_{c, \mathrm{Co}_{3} W}^{L 12}$ for a wide range of alloying elements is suggested as an ideal means of rapidly screening elements for their potential to enter the $\mathrm{W}$ sublattice in $\mathrm{Co}_{3} \mathrm{~W}$. 


\section{Conclusions}

Site preference and Vegard's coefficients of several alloying elements were probed in $\mathrm{L}_{2}-\mathrm{Co}_{3} \mathrm{~W}$. It is found that site preference is strongly dependent of size mismatch and electronegativity difference between X, and Co and W. The stability of $\mathrm{Co}_{3} \mathrm{X}$ compounds was probed in different structures and it was shown that heat of formation could be used to predict if $\mathrm{Co}_{3} \mathrm{X}$ itself can be stabilized in $\mathrm{L}_{2}$ and if $\mathrm{X}$ will prefer a $\mathrm{W}$ site or a Co site if added to $\mathrm{Co}_{3} \mathrm{~W}$.

The authors acknowledge the support of Department of Science and Technology, Government of India.

\section{References}

[1] J. Sato, T. Omori, K. Oikawa, I. Ohnuma, R. Kainuma and K. Ishida, Science, 312, 90 (2006)

[2] R, C. Reed, The Superalloys: Fundamentals and Applications, Cambridge University Press (2006)

[3] A. M. Beltran In: Superalloys II. New york (NY): Wiley; 135 (1987)

[4] M. S. Titus, A. Suzuki, T. M. Pollock, Proceedings of $12^{\text {th }}$ international symposium on Superalloys 2012 , 823 (2012)

[5] A. Bauer, S. Neumeie, F. Pyczak, M. Göken, Proceedings of $12^{\text {th }}$ international symposium on Superalloys 2012, 695 (2012)

[6] A. Suzuki, T. M. Pollock, Acta. Mater. 56, 1288 (2008)

[7] K. Tanaka, T. Ohashi, K. Kishida, and H. Inui, Appl. Phy. Lett., 91, 181907 (2007)

[8] K. Shinagawa, T. Omori, K. Oikawa, R. Kainuma and K. Ishida Scri. Mater., 61, 612 (2009)

[9] F. Pyczak, A. Bauer, M. Göken, S. Neumeier, U. Lorenz, M. Oehring, N. Schell, A. Schreyer, A. Stark, F. Symanzik, Mater..Sci. Eng., A 571, 13 (2013)

[10] M. Chen and C. Y. Wang J. Appl Phy., 107, 093705 (2010)

[11] M. Chen and C. Y. Wang Scri. Mater., 60, 659 (2009)

[12] A. Mottura, A. Janotti, T. M. Pollock, Proceedings of $12^{\text {th }}$ international symposium on Superalloys 685 (2012)

[13] Q. Yao, H. Xing, and J. Sun, Appl. Phy. Lett., 89, 161906 (2006)

[14] C Jiang, Scri. Mater., 59, 1075 (2008)
[15] Y. J. Wang and C. Y. Wang, Appl. Phy. Lett., 94, 261909 (2009)

[16] M. Chen and C. Y. Wang, J. Appl. Phy., 107, 093705 (2010)

[17] M. Chen and C. Y. Wang, Scri. Mater., 60, 659 (2009)

[18] JM Blaise, P. Viatour and J. M. Drapier Cobalt (Engl Ed) 49, 192 (1970)

[19] J. M. Drapier, J. L. De Brouwer and D. Coutsouradis Cobalt (Engl Ed) 27, 59 (1965)

[20] E. T. Peters and L. E. Tanner, Trans. Metall. Soc. AIME 233, 2126 (1965)

[21] Y. Aoki, K. Asami and M. Yamamoto, Phys Stat. Sol. (A)., 23, 167 (1974)

[22] W. W. Xu, J. J. Han, Z. W. Wang, C. P. Wang, Y. H. Wen, X. J. Liua and Z. Z. Zhu Intermetallics 32, 303 (2013)

[23] T. Omori, K. Oikawa, J, Sato, I. Ohnuma, U. R. Kattner, R. Kainuma and K. Ishida Intermetallics 32, 274 (2013)

[24] K V Vamsi and S Karthikeyan, Proceedings of the 12th international symposium on Superalloys 0521 (2012)

[25] K. V. Vamsi and S. Karthikeyan, Unpublished

[26] G. Kresse and J. Furthmiller, Phys Rev B 54, 11169 (1996)

[27] G. Kresse and J. Furthmiller J. Comp Mater Sci 6, 15 (1996)

[28] MedeA Version 2.6.6 Materials Design Inc, Angel Fire, NM, USA (2009)

[29] P. E. Blochl, Phys Rev B 50, 17953 (1994)

[30] G. Kresse and D. Joubert Phys Rev B 159, 1758 (1999)

[31] J. P. Perdew, K. Burke and M. Ernzerhof Phys Rev Lett 77, 3865 (1996)

[32] W. Hume-Rothery and G. V. Raynor The Structure of Metals and alloys, The Institute of Metals (1956)

[33] A. R. Miedema, Journal of the Less-Common Metals 32, 117 (1973)

[34] W. Pfeiler Alloy Physics Wiley-VCH Verlag GmbH \& Co. (2007)

[35] T. N. Rezukhina and T. A. Kashina, J. Chem Thermodynamics 8, 513 (1976)

[36] K. Oikawa, U. R. Kattner, J. Sato, T. Omori, M. Jiang, K. Anzai and K. Ishida Materials Transactions 53, 1425 (2012)

[37] L. Brewer, R. H. Lamoreaux, R. Ferro, R. Ma razza and K. Girgis, Molybdenum IAEA 7, $123 \& 231$ (1980) 